\title{
A Review of Self-Regulated Learning and Self-Efficacy: The Key to Tertiary Transition in Science, Technology, Engineering and Mathematics (STEM)
}

\author{
Conner Blackmore ${ }^{1}$, Julian Vitali ${ }^{2}$, Louise Ainscough ${ }^{3}$, Tracey Langfield ${ }^{3} \&$ Kay Colthorpe ${ }^{3}$ \\ ${ }^{1}$ School of Medicine, University of Notre Dame Australia, Fremantle, Western Australia, Australia \\ ${ }^{2}$ School of Medicine Notre Dame Australia, School of Medicine The University of Queensland, Australia \\ ${ }^{3}$ School of Biomedical Sciences, The University of Queensland, Australia \\ Correspondence: Conner Blackmore, School of Medicine, University of Notre Dame Australia, Fremantle, Western \\ Australia, Australia. \\ * Conner Blackmore and Julian Vitali are joint $1^{\text {st }}$ authors.
}

Received: November 12, 2020

Accepted: January 13, 2021

Online Published: January 18, 2021

doi:10.5430/ijhe.v10n3p169

URL: https://doi.org/10.5430/ijhe.v10n3p169

\begin{abstract}
The ability to distinguish between effective and ineffective study strategies based on feedback is of utmost importance for secondary school leavers transitioning to tertiary education (Brinkworth et al., 2009; Salisbury \& Karasmanis, 2011). Often accompanying this learning environment transition is academic difficulty and an increased possibility of failure, and it is therefore essential for undergraduate students, in particular those studying the disciplines of Science, Technology, Engineering and Maths (STEM), to establish a solid repertoire of learning strategies early in their academic career. Self-regulation is a key component of learning that can be fostered to encourage a successful transition from secondary school to university (Vosniadou, 2020). Self-regulated learning refers to learning that is fostered by one's metacognition, strategy adaptability, and motivation. Of these constructs, metacognition is fundamental, as having self-awareness allows one to identify the requirement for corrective action in the learning process, allowing learners to monitor their behaviour and reflect on the success of their learning strategies, where the motivation to do this should lead to strategy adaptation. In addition, students must make accurate self-efficacious judgements about their learning in order to evaluate the effectiveness of their learning strategies or to decide when they have sufficiently completed a learning task. Therefore, in order to develop a means of improving students' transition from secondary school to university, one must first appreciate the impacts of self-regulated learning and self-efficacy on academic performance. This review aims to focus on self-regulated learning and self-efficacy, of which self-regulated learning is a construct of metacognition, motivation and strategy adaptability. This review will also evaluate self-regulated learning with an emphasis on Zimmerman's model, the calibration of self-efficacy, and how students might break the cycle of poor learning with a focus on STEM.
\end{abstract}

Keywords: academic performance, metacognition, STEM, self-efficacy

\section{Introduction}

The ability to distinguish between effective and ineffective study strategies based on feedback is of utmost importance for secondary school leavers transitioning to tertiary education (Abbott-Chapman et al., 1992; Beaumont et al., 2016; Lee et al., 2010)_Increased student autonomy and independence of study across all learning domains at university can be both confronting and difficult to master (Van der Meer et al., 2010; Vitali, Blackmore, Mortazavi and Anderton 2020). Often accompanying this learning environment transition is academic difficulty and an increased possibility of failure (Hall \& Sverdlik, 2016; Alspaugh, 1998; Vitali et al., 2020). Specifically, introductory anatomy and physiology courses, a major component of STEM foundational courses, experience some of the highest failure rates across undergraduate courses (Higgins-Opitz \& Tufts, 2014). It is therefore essential for undergraduate students studying these disciplines to establish a solid repertoire of learning strategies early in their academic career.

Self-regulation is a key component of learning that can be fostered to encourage a successful transition from secondary school to university. Self-regulated learning refers to learning that is directed by one's metacognition, strategy adaptability, and motivation (Butler and Winne, 1995; Panadero, 2017). Metacognition is the awareness, 
knowledge and understanding of one's thinking (Zimmerman, 2002), which is important for students facing more autonomy than usual. Metacognition is fundamental, as having self-awareness allows one to identify the requirement for corrective action in the learning process (Zimmerman, 2002). This allows learners to monitor their behaviour and reflect on the success of their learning strategies for the next learning cycle (Zimmerman, 2002).

However, the need to understand student learning patterns is based on far more than just the potential ramifications of an unsuccessful transition to university. Research suggests that learners' academic potential does not consistently reflect their academic outcomes (Mahmud, 2014; Sullivan \& Guerra, 2007; Zimmerman, 1990), which implies that intrinsic factors such as self-efficacy (Locke \& Latham, 2002) and the ability to self-regulate (Boekaerts, 1999), may influence the pathway of academic outcomes (Schunk, 2005; Vitali et al., 2020). Students need to make accurate self-efficacious judgements about their learning in order to evaluate the effectiveness of their learning strategies or to decide when they have sufficiently completed a learning task. Therefore, in order to develop a means of improving students' transition from school to university, one must first appreciate the impacts of self-regulated learning and self-efficacy on academic performance. This review will evaluate self-regulated learning theories, the calibration of self-efficacy, and how students might break the cycle of poor learning with a focus on STEM.

\section{Self-regulated Learning Theories}

Zimmerman (2002) defines self-regulated learning as a self-directed process through which learners transform their cognitive abilities into academic dexterity. A well-established self-regulated learner will utilize many strategies for effective problem solving and learning, whilst concurrently restructuring their thoughts, feelings and behaviours to optimise learning (Borkowski, 1996; Colthorpe et al., 2015). Being a competent self-regulated learner can increase motivation and consequently academic achievement (Schunk \& Zimmerman, 1998; Zimmerman, 2000; Zimmerman \& Schunk, 2011), and metacognition is imperative to the success of these processes (Colthorpe et al., 2018; Jackson, 2004; Laskey \& Hetzel, 2010; Winne, 2018). Having an awareness of one's cognition allows the learner to reflect on the effectiveness of their study strategies, leading to adaptations in their approach to study during future learning cycles.

A number of self-regulated learning theories have been proposed (Panadero, 2017; Puustinen \& Pulkkinen, 2001; Winne \& Hadwin, 2013; Borkowski, 1996; Boekaerts, 1999; Pintrich, 2000). Boekaerts' (1999) theory_of self-regulated learning emphasises a balance of positive and negative appraisals of one's work, where optimal learning conditions provide the opportunity for knowledge gain while the student experiences a felt necessity to learn. Boekaerts' theory was presented as a three-layered model; the innermost layer pertaining to regulation of the processing modes, the middle layer representing regulation learning processes, and the outermost layer concerning regulation of self (Boekaerts, 1999). Borkowski (1996) conceives a process-orientated model of metacognition in which the successful integration of cognitive, motivational, personal and situational components provides the platform for information processing and learning. The Pintrich (2000) model of self-regulated learning focuses on integration of motivational constructs, such as expectancy, value and affect. This model of self-regulated learning consisted of numerous phases, which provided a comprehensive picture that includes a significant number of self-regulated learning process (e.g. prior content knowledge activation, efficacy judgements, self-observations of behaviour); and although there is only one version it has provided major contributions to clarifying the self-regulated learning framework for future models (Panadero, 2017). Lastly, the Zimmerman (2002) model of self-regulated learning consists of forethought, performance and self-reflection phases, which are cyclically adapted.

\subsection{Zimmerman's Model}

Zimmerman's model is arguably the most prominent and widely used theory of self-regulated learning (Panadero \& Alonso-Tapia, 2014). This model has formed the basis for several educational interventions (Zimmerman \& Martinez-Pons, 1992; Stanton et al., 2015; Zimmerman et al., 2011; Ramdass \& Zimmerman, 2008), health investigations (Zimmerman et al., 1999), even athletics related studies (Cleary \& Zimmerman, 2001), and is well supported in the contemporary literature.

Zimmerman's (2002) model begins at the forethought phase, where a learner must analyse the task at hand in order to set goals and plan strategies for attaining these targets. The forethought phase also includes one's self-efficacy (Bandura, 2010), intrinsic motivation to succeed, learning goal orientation and outcome expectations. These factors contribute to both the level of effort expended and the degree of difficulty (Schunk, 2005).

The forethought phase prepares a learner for the performance phase where learning activities are completed. During the performance phase a learning task is attempted, and the learner puts techniques of self-control such as attention focusing, task strategies and imagery into practice (Zimmerman \& Martinez-Pons, 1992; Zimmerman \& Moylan, 
2009). In addition to self-control techniques, the performance phase includes self-observation, where students record and experiment with learning strategies. A student might note the effort placed into revision and experiment with different learning strategies, for example, studying in a group when one typically studies alone (Zimmerman, 2002).

The self-reflection phase completes Zimmerman's cyclical model of self-regulated learning. There are two major sub-processes within the self-reflection phase: self-judgment and self-reaction. Self-judgment includes self-evaluation, where a learner compares their performance against standards, such as previous experience with the task, the results of peers or extrinsic feedback (Kitsantas \& Dabbagh, 2013). A second aspect of self-judgment is causal attribution, referring to beliefs about the cause of one's success or failures (Zimmerman, 2002). These components, combined with self-motivational beliefs, determine a student's self-reaction. How satisfied a student is with their performance and how they then choose to adapt their learning strategies completes the learning cycle, but also prompts expectations for future forethought and subsequent performance. This is important, as it would appear that students who possess the ability to detect subtle developments in their learning across iterations are more likely to enhance their self-satisfaction and self-efficacy over time, leading to improved academic achievement (Schunk, 1982; Zimmerman \& Schunk, 2011).

\section{Self-Efficacy}

Not only is self-efficacy part of the self-regulated learning cycle, it is also an important motivational construct in its own right (Bandura, 2010; Zimmerman, 2000; Zimmerman \& Schunk, 2011). Self-efficacy can be defined as the personal belief in one's ability to perform a task (Artino, 2012; Bandura, 1986). Self-efficacy is developed through reciprocal causation, where one's skill in a task and self-efficacy influence each other to develop success through action. However, Bandura (1986) also advised that the optimal level of self-efficacy varies depending on what one seeks to achieve; self-efficacy is important for all aspects of life (Bandura, 2010) not just academia, and the required level of self-efficacy to succeed in a tertiary exam may not match the self-efficacy required to play golf. Self-efficacy beliefs are typically derived from four chief sources (Artino, 2012; Bandura, 1986; Zuffiano et al., 2013):

1) Enactive mastery: One's actual performance over time.

2) Observation of others: assessment of one's ability compared with other students or by observing a demonstration.

3) Social support/verbal persuasion: forms of persuasion from both peers and mentors.

4) Physiological and affective states: a state of being, for example, nervous, fatigued or mood state.

Of these sources, enactive mastery is regarded as having the most powerful influence on self-efficacy beliefs (Artino, 2012; Bandura, 1986; Zuffiano et al., 2013).

Bandura (1986) suggests that promoting self-efficacy is imperative and that educators should do this throughout a students' educational experience by providing numerous opportunities for success. Evidence suggests a positive correlation between self-efficacy and academic achievement (Pintrich \& DeGroot, 1990; Komarraju \& Nadler, 2013). Students with high self-efficacy are more likely to believe their intelligence is malleable, and therefore study harder in the face of academic challenges and attempt to adapt their learning in the face of adversity (Locke \& Latham, 2002, Komarraju \& Nadler, 2013, Wright et al., 2012). More marked, however, is the association between low self-efficacy and reduced academic achievement (Burgoon et al., 2012). This finding by Burgoon et al. (2012) may hold the key to successful academic interventions. If an intervention could enhance self-efficacy, students' levels of academic achievement may simultaneously increase.

\subsection{Science Self-Efficacy}

Improving self-efficacy in the fields of science, technology, engineering and mathematics (STEM) is particularly important, as introductory STEM courses experience some of the highest failure rates (Higgins-Opitz \& Tufts, 2014). There is a strong correlation between academic achievement, persistence and self-efficacy in a variety of science disciplines, including mathematics (Pajares \& Graham, 1999; Skaalvik et al., 2015), chemistry (Cook, 2013) and physics (Fencl \& Scheel, 2005; Sawtelle et al., 2012). Anatomy is one science discipline that students often struggle with, potentially because the broader picture of anatomy is difficult to teach (Fitzpatrick et al., 2001; Vitali et al., 2020). Those studying anatomy in physiotherapy and medicine are typically considered to be high achievers due to the competitive entry requirements of their degrees (Ranasinghe et al., 2012), as such these students are more likely to have good metacognitive awareness. Burgoon et al. (2012) investigated the impact of gross anatomy self-efficacy beliefs in first year medical students, demonstrating a positive correlation between gross anatomy self-efficacy ratings and academic outcomes, reportedly due to enactive mastery experiences. It is therefore expected that those students with lower self-efficacy will struggle while studying anatomy at university. What then was the 
distinguishing factor for success? Burgoon et al. (2012) hypothesised that students who chose to carry out more dissection and cadaveric study gained more experience and knowledge in gross anatomy and consequently held higher self-efficacy beliefs. These beliefs in turn correlated with better academic outcomes than their less practiced and exposed peers.

Gender differences in STEM self-efficacy are also well documented (Ainscough et al., 2016; Bell \& Volckmann, 2011; Fallan \& Opstad, 2016), with females typically expressing lower self-efficacy than males. Bell and Volckmann (2011) also found that males often overestimate their ability to perform tasks, resulting in higher self-efficacy. This is somewhat alarming, considering that students with higher self-efficacy persist longer at college and have higher success rates than their counterparts with lower self-efficacy (Mattern et al., 2010). Likewise, Seymour (1992) found a decline in females pursuing STEM related careers across all levels because of self-doubt. While the relationship between self-efficacy and academic achievement is less consistent when evaluated based on gender in the field of STEM, the overall outcome is concerning. Typically, females perform at a higher level in introductory anatomy and physiology courses when compared to their male counterparts (Vitali et al., 2020). However, possibly due to lower self-efficacy, females tend to persist less in the field of STEM (Seymour, 1992; Stout et al., 2011).

\section{Calibration of Self-Efficacy}

This positive correlation between self-efficacy and academic achievement may suggest that high self-efficacy is inherently good; however, Ainscough et al. (2016), found that high self-efficacy ratings do not necessarily correlate with high academic achievement. For a learner to change ineffective study habits or behaviours, they must first recognise their shortcomings and the requirement to adapt their learning strategies. This task is far from simple. Kruger and Dunning (1999) made this discovery while testing participants across the domains of humour, logical reasoning, and English grammar literacy. They discovered that participants scoring in the lowest quartile on standardised tests consistently over-estimated their performance. The authors concluded that these participants were both unskilled and unaware of their shortcomings. In contrast, those in the top quartile underestimated their achievement because they assumed that other participants would perform equally well. Dunning et al. (2003) replicated these results across a senior university psychology class.

This discrepancy between perceived test performance and actual test performance has been termed the 'Dunning-Kruger Effect' (Kruger \& Dunning, 1999). These inaccurate confidence judgments are commonly termed 'miscalibrations', a measure in the difference between confidence in performing a specific activity (self-efficacy) versus actual performance in that activity (academic achievement) (Artino, 2012). Those suffering from the Dunning-Kruger Effect are unaware of the knowledge they lack (Pazicni \& Bauer, 2014). In addition, Zell and Krizan (2014) determined that increased task complexity results in decreased ability to form accurate judgements of skill level. Interestingly, this suggests that if students were taught how to distinguish right from wrong on examination questions, they would be able to recognise their shortcomings. However, in this phenomenon a paradox exists: if students had the skills necessary to distinguish correct from incorrect answers, they would not be underperforming. Kruger and Dunning (1999) demonstrated that students in the lower quartile on a logic test were better able to calibrate their performance judgements if they were provided with instructions on logical reasoning after completing the test. Essentially the authors trained students in logical reasoning so that they could recognise their prior poor performance, therefore reducing the significance of the Dunning-Kruger Effect.

It should be noted however that most students do not receive the detailed instruction like that provided by Kruger and Dunning (1999) during their university studies. Although students are provided with feedback at university, not all are equally able to process feedback. Students with well-developed self-regulatory skills are more able to generate self-feedback and act on external feedback (Butler \& Winne, 1995; Nicol \& Macfarlane-Dick, 2006; Schunk \& Zimmerman, 2012), providing these students with a stronger foundation for developing accurate self-efficacy. This is supported by the finding that lower performing students employ metacognitive strategies less frequently than their higher performing counterparts (Pazicni \& Bauer, 2014). In addition, Ehrlinger et al. (2008) suggest that people base their ability to perform a task on previously conceived beliefs about their skill and knowledge rather than past performance. This is known as 'top-down' processing (Hacker et al., 2000), and suggests that in the academic arena, some students may inadvertently ignore feedback because they have less well-developed metacognitive skills. However, Nietfeld et al. (2006) showed that promoting monitoring skills through metacognitive exercises actually enhances mastery, which demonstrates that metacognitive skills are trainable, whilst suggesting that type and level of feedback plays an important role. For example, Nease et al. (1999) illustrated that over time students adapt their self-efficacy to correlate with feedback, but only if they value the feedback as reasonable and within their acceptance rate (not aggressively harsh, not unrealistically positive). Similarly, Silver et al. (1995) illustrated that individuals' 
reaction to feedback, both negative and positive, is moderated by their level of self-efficacy.

\subsection{Self-Efficacy Calibration Interventions}

Few studies have attempted to directly manipulate student self-efficacy. Ramdass and Zimmerman (2008) developed an intervention for school students which included strategy training in mathematics and a technique for generating self-feedback on the accuracy of their answers, finding that the intervention group had more accurate self-efficacy and higher academic outcomes. Zimmerman et al. (2011) went on to design a similar intervention for college students, with similar results. These studies indicate that self-regulatory strategy training can enhance students' self-efficacy accuracy, self-regulation ability and academic achievement. In contrast, Hall and Sverdlik (2016) implemented an attributional retraining program to lower students' academic expectations. Students were given an aptitude test designed to invoke a failure experience followed by a reading and writing exercise to encourage students to adopt intrinsic explanations for academic shortcomings, rather than blaming extrinsic factors which typically safeguard one's self-efficacy (Kruger \& Dunning, 1999). They found that students had higher performance expectations but no benefit to student goal orientation, and participants maintained significantly lower grades over the recorded five subsequent semesters at university. These results may be contradictory to earlier studies because of the lack of academic support or strategy training.

\section{Breaking the Cycle of Poor Self-Regulation}

How might it be possible to break the cycle of poor self-regulation, and how will this impact on poor academic performance? We know that self-regulation is a cyclical process, but students can only improve their approach in each iteration if they are able to accurately evaluate the cause of their performance, and adapt their learning strategies (Zimmerman, 2002). If this is not achieved, the consequences are a cyclical learning pattern with reinforcement of negative behaviours. Accurate self-efficacy measures are imperative for setting achievable and realistic goals in the forethought phase, which are then used during self-evaluation as a benchmark of success. Therefore, accurate self-efficacy is fundamental for self-evaluation. Likewise, self-evaluation is also vital as a lack of self-evaluation will result in self-efficacy beliefs stemming from incorrect views about performance ability (Ehrlinger et al., 2008), likely manifesting in suboptimal academic achievement.

While there are numerous discrete predictive factors that influence student transition and performance in tertiary STEM subjects, such as high school subject selection (Blackmore et al., 2021), gender and study strategies (Vitali et al., 2020), there still exists a need for a broadly implemented strategy to improve student outcomes. Meta-learning activities, originally coined by Biggs (1985), both monitor and enhance student metacognitive awareness (Colthorpe et al., 2018), these activities are further justified through the work of Zimmerman and Bandura (1994), Schunk and Zimmerman (1998) and Nietfeld et al. (2006), who advocate the effectiveness of such metacognitive exercises. Colthorpe et al. (2019) has demonstrated that a variety of forethought and self-reflection sub-processes correlate with academic outcomes, including self-efficacy. In addition, self-evaluation correlates with other forethought and self-reflection sub-processes, illustrating its value as an intervention target. By implementing interventions to improve these learning processes in undergraduate programs, particularly within the field of STEM where students chronically struggle to transition academically, improved results, learning and persistence can be expected.

\section{Significance}

A comprehensive understanding of STEM, and anatomy as an extension, is not only important to academic performance, translating to overall university grade point average (Anderton \& Chivers, 2006), it is crucial for clinical success in medical, occupational therapy and physiotherapy professions (Forester et al., 2002). As the autonomy required of tertiary study varies significantly from that of high school (Vitali et al., 2020), students must develop new and effective learning strategies. Metacognition is integral to this strategy development and adaptation. Having the ability to self-regulate, an effectively calibrated self-efficacy, and the ability to perform productive self-evaluations is paramount in the quest for academic, and more importantly, clinical success because of the positive effect these qualities have on lifelong learning (Cornford, 2002).

\section{References}

Abbott-Chapman, J. A., Hughes, P. W., \& Wyld, C. (1992). Monitoring student progress: A framework for improving student performance and reducing attrition in higher education. National Clearinghouse for Youth Studies, Australia.

Ainscough, L., Foulis, E., Colthorpe, K., Zimbardi, K., Robertson-Dean, M., Chunduri, P., \& Lluka, L. (2016). Changes in Biology Self-Efficacy during a First-Year University Course. CBE-Life Sciences Education, 15(2), ar19. https://doi.org/10.1187/cbe.15-04-0092 
Alspaugh, J. W. (1998). Achievement loss associated with the transition to middle school and high school. The Journal of Educational Research, 92(1), 20-25. https://doi.org/10.1080/00220679809597572

Anderton, R., \& Chivers, P. (2016). Predicting academic success of health science students for first year anatomy and physiology. International Journal of Higher Education, 5(1), 250-260. https://doi.org/10.5430/ijhe.v5n1p250

Artino, A. R. Jr. (2012). Academic self-efficacy: from educational theory to instructional practice. Perspect Med Educ, 1(2), 76-85. https://doi.org/10.1007/s40037-012-0012-5

Bandura, A. (1986). Social foundations of thought and action: A social cognitive theory, Prentice-Hall, Inc. https://doi.org/10.5465/amr.1987.4306538

Bandura, A. (2006). Guide for constructing self-efficacy scales. Self-efficacy beliefs of adolescents, 5(1), 307-337.

Bandura, A. (2010). Self-efficacy. The Corsini encyclopedia of psychology, 1-3. https://doi.org/10.1002/9780470479216.corpsy0836

Beaumont, C., Moscrop, C., \& Canning, S. (2016). Easing the transition from school to HE: Scaffolding the development of self-regulated learning through a dialogic approach to feedback. Journal of Further and Higher Education, 40(3), 331-350. https://doi.org/10.1080/0309877X.2014.953460

Bell, P., \& Volckmann, D. (2011). Knowledge surveys in general chemistry: confidence, overconfidence, and performance. Journal of Chemical Education, 88, 1469-1476. https://doi.org/10.1021/ed100328c

Biggs, J. B. (1985). The role of meta-learning in study processes. British journal of educational psychology, 55(3), 185-212. https://doi.org/10.1111/j.2044-8279.1985.tb02625.x

Biggs, J. B. (1987). Student Approaches to Learning and Studying. Research Monograph. Australian Council for Educational Research Ltd.

Blackmore, C., Hird, K., \& Anderton, R. S. (2021). An Investigation of Secondary School STEM Subjects as Predictors of Academic Performance in Tertiary Level Health Sciences Programs. International Journal of Higher Education, 10(1), 76-84. https://doi.org/10.5430/ijhe.v10n1p76

Boekaerts, M. (1999). Self-regulated learning: Where we are today. International journal of educational research, 31(6), 445-457. https://doi.org/10.1016/S0883-0355(99)00014-2

Borkowski, J. G. (1996). Metacognition: Theory or chapter heading? Learning and individual differences, 8(4), 391-402. https://doi.org/10.1016/S1041-6080(96)90025-4

Brinkworth, R., McCann, B., Matthews, C., \& Nordström, K. (2009). First year expectations and experiences: Student and teacher perspectives. Higher Education, 58(2), 157-173. https://doi.org/10.1007/s10734-008-9188-3

Burgoon, J. M., Meece, J. L., \& Granger, N. A. (2012). Self-efficacy's influence on student academic achievement in the medical anatomy curriculum. Anatomical sciences education, 5(5), 249-255. https://doi.org/10.1002/ase.1283

Butler, D. L., \& Winne, P. H. (1995). Feedback and self-regulated learning: A theoretical synthesis. Review of educational research, 65(3), 245-281. https://doi.org/10.3102/00346543065003245

Cleary, T. J., \& Zimmerman, B. J. (2001). Self-regulation differences during athletic practice by experts, non-experts, and novices. Journal of Applied Sport Psychology, 13(2), 185-206. https://doi.org/10.1080/104132001753149883

Colthorpe, K., Ogiji, J., Ainscough, L., Zimbardi, K., \& Anderson, S. (2019). Effect of metacognitive prompts on undergraduate pharmacy students' self-regulated learning behavior. American Journal of Pharmaceutical Education, 83(4). https://doi.org/10.5688/ajpe6646

Colthorpe, K., Sharifirad, T., Ainscough, L., Anderson, S., \& Zimbardi, K. (2018). Prompting undergraduate students' metacognition of learning: implementing 'meta-learning' assessment tasks in the biomedical sciences. Assessment \& Evaluation in Higher Education, 43(2), 272-285. https://doi.org/10.1080/02602938.2017.1334872

Colthorpe, K., Zimbardi, K., Ainscough, L., \& Anderson, S. (2015). Know thy student! Combining learning analytics and critical reflections to develop a targeted intervention for promoting self-regulated learning. Journal of Learning Analytics, 2(1), 134-155. https://doi.org/10.18608/jla.2015.21.7

Cook, A. F. (2013). Exploring freshmen college students' self-efficacy, attitudes, and intentions toward chemistry. West Kentucky University. 
Cornford, I. R. (2002). Learning-to-learn strategies as a basis for effective lifelong learning. International Journal of Lifelong Education, 21(4), 357-368. https://doi.org/10.1080/02601370210141020

Dunning, D., Johnson, K., Ehrlinger, J., \& Kruger, J. (2003). Why people fail to recognize their own incompetence. Current Directions in Psychological Science, 12(3), 83-87. https://doi.org/10.1111/1467-8721.01235

Ehrlinger, J., Johnson, K., Banner, M., Dunning, D., \& Kruger, J. (2008). Why the unskilled are unaware: Further explorations of (absent) self-insight among the incompetent. Organizational behavior and human decision processes, 105(1), 98-121. https://doi.org/10.1016/j.obhdp.2007.05.002

Fallan, L., \& Opstad, L. (2016). Student Self-Efficacy and Gender-Personality Interactions. International Journal of Higher Education, 5(3), 32-44. https://dx.doi.org/10.5430/ijhe.v5n3p32

Fencl, H., \& Scheel, K. (2005). Engaging students. Journal of College Science Teaching, 35(1), 20-24.

Fitzpatrick, C. M., Kolesari, G. L., \& Brasel, K. J. (2001). Teaching anatomy with surgeons' tools: Use of the laparoscope in clinical anatomy. Clinical Anatomy: The Official Journal of the American Association of Clinical Anatomists and the British Association of Clinical Anatomists, 14(5), 349-353. https://doi.org/10.1002/ca.1062

Forester, J. P., Mcwhorter, D. L., \& Cole, M. S. (2002). The relationship between premedical coursework in gross anatomy and histology and medical school performance in gross anatomy and histology. Clinical Anatomy The Official Journal of the American Association of Clinical Anatomists and the British Association of Clinical Anatomists, 15(2), 160-164. https://doi.org/10.1002/ca.1114

Hacker, D. J., Bol, L., Horgan, D. D., \& Rakow, E. A. (2000). Test prediction and performance in a classroom context. Journal of Educational Psychology, 92(1), 160. https://doi.org/10.1037/0022-0663.92.1.160

Hall, N. C., \& Sverdlik, A. (2016). Encouraging Realistic Expectations in STEM Students: Paradoxical Effects of a Motivational Intervention. Frontiers in Psychology, 7. https://doi.org/10.3389/fpsyg.2016.01109

Higgins-Opitz, S. B., \& Tufts, M. (2014). Performance of first-year health sciences students in a large, diverse, multidisciplinary, first-semester, physiology service module. Advances in physiology education, 38(2), 161-169. https://doi.org/10.1152/advan.00067.2013

Jackson, N. (2004). Developing the concept of metalearning. Innovations in Education and Teaching International, 41(4), 391-403. https://doi.org/10.1080/1470329042000276995

Jaspers, M. W., Steen, T., Van Den Bos, C., \& Geenen, M. (2004). The think aloud method: a guide to user interface design. International journal of medical informatics, 73(11-12), 781-795. https://doi.org/10.1016/j.ijmedinf.2004.08.003

Kitsantas, A., \& Dabbagh, N. (2013). Learning to Learn with Integrative Learning Technologies (ILT): A Practical Guide for Academic Success (Chinese Edition). IAP.

Komarraju, M., \& Nadler, D. (2013). Self-efficacy and academic achievement: Why do implicit beliefs, goals, and effort regulation matter? Learning and Individual Differences, $25, \quad 67-72$. https://doi.org/10.1016/j.lindif.2013.01.005

Kruger, J., \& Dunning, D. (1999). Unskilled and unaware of it: how difficulties in recognizing one's own incompetence lead to inflated self-assessments. Journal of personality and social psychology, 77(6), 1121. https://doi.org/10.1037/0022-3514.77.6.1121

Laskey, M. L., \& Hetzel, C. J. (2010). Self-Regulated Learning, Metacognition, and Soft Skills: The 21st Century Learner. Online submission.

Lee, H. W., Lim, K. Y., \& Grabowski, B. L. (2010). Improving self-regulation, learning strategy use, and achievement with metacognitive feedback. Educational Technology Research and Development, 58(6), 629-648. https://doi.org/10.1007/s11423-010-9153-6

Locke, E. A., \& Latham, G. P. (2002). Building a practically useful theory of goal setting and task motivation: A 35-year odyssey. American psychologist, 57(9), 705. https://doi.org/10.1037/0003-066X.57.9.705

Mahmud, M. M. (2014). Communication aptitude and academic success. Procedia-Social and Behavioral Sciences, 134, 125-133. https://doi.org/10.1016/j.sbspro.2014.04.230

Mattern, K. D., Burrus, J., \& Shaw, E. (2010). When both the skilled and unskilled are unaware: Consequences for academic performance. Self and Identity, 9(2), 129-141. https://doi.org/10.1080/15298860802618963

Nease, A. A., Mudgett, B. O., \& Quiñones, M. A. (1999). Relationships among feedback sign, self-efficacy, and acceptance of performance feedback. Journal of Applied Psychology, 84(5), 806. 
https://doi.org/10.1037/0021-9010.84.5.806

Nicol, D. J., \& Macfarlane-Dick, D. (2006). Formative assessment and self-regulated learning: A model and seven principles of good feedback practice. Studies in higher education, 31(2), 199-218. https://doi.org/10.1080/03075070600572090

Nietfeld, J. L., Cao, L., \& Osborne, J. W. (2006). The effect of distributed monitoring exercises and feedback on performance, monitoring accuracy, and self-efficacy. Metacognition and Learning, 1(2), 159-179. https://doi.org/10.1007/s10409-006-9595-6

Panadero, E. (2017). A review of self-regulated learning: Six models and four directions for research. Frontiers in psychology, 8, 422. https://doi.org/10.3389/fpsyg.2017.00422

Panadero, E., \& Alonso-Tapia, J. (2014). How do students self-regulate? Review of Zimmerman's cyclical model of self-regulated learning. Anales de psicologia, 30(2), 450-462. https://doi.org/10.6018/analesps.30.2.167221

Pazicni, S., \& Bauer, C. F. 2014. Characterizing illusions of competence in introductory chemistry students. Chemistry Education Research and Practice, 15(1), 24-34. https://doi.org/10.1039/C3RP00106G

Pintrich, P. R. (2000). The role of goal orientation in self-regulated learning. In Handbook of self-regulation (pp. 451-502). Academic Press. https://doi.org/10.1016/B978-012109890-2/50043-3

Pintrich, P. R., \& DeGroot, E. (1990). Quantitative and qualitative perspectives on student motivational beliefs and self-regulated learning. In Annual Meeting of the American Educational Research Association, Boston, MA (Vol. 128).

Puustinen, M., \& Pulkkinen, L. (2001). Models of self-regulated learning: A review. Scandinavian Journal of Educational Research, 45(3), 269-286. https://doi.org/10.1080/00313830120074206

Ramdass, D., \& Zimmerman, B. J. (2008). Effects of self-correction strategy training on middle school students' self-efficacy, self-evaluation, and mathematics division learning. Journal of advanced academics, 20(1), 18-41. https://doi.org/10.4219/jaa-2008-869

Ranasinghe, P., Ellawela, A., \& Gunatilake, S. B. (2012). Non-cognitive characteristics predicting academic success among medical students in Sri Lanka. BMC Med Edu, 12(66). https://doi.org/10.1186/1472-6920-12-66

Salisbury, F., \& Karasmanis, S. (2011). Are they ready? Exploring student information literacy skills in the transition from secondary to tertiary education. Australian Academic \& Research Libraries, 42(1), 43-58. https://doi.org/10.1080/00048623.2011.10722203

Sawtelle, V., Brewe, E., \& Kramer, L. H. (2012). Exploring the relationship between self-efficacy and retention in introductory physics. Journal of research in science teaching, 49(9), 1096-1121. https://doi.org/10.1002/tea.21050

Schunk, D. H. (1982). Progress self-monitoring: Effects on children's self-efficacy and achievement. The Journal of Experimental Education, 51(2), 89-93. https://doi.org/10.1080/00220973.1982.11011845

Schunk, D. H. (2005). Self-regulated learning: The educational legacy of Paul R. Pintrich. Educational Psychologist, 40(2), 85-94. https://doi.org/10.1207/s15326985ep4002_3

Schunk, D. H., \& Zimmerman, B. J. (1998). Self-regulated learning: From teaching to self-reflective practice, Guilford Press.

Schunk, D. H., \& Zimmerman, B. J. (2012). Self-regulation and learning. Handbook of Psychology, Second Edition, 7. https://doi.org/10.1002/9781118133880.hop207003

Seymour, E. (1992). Undergraduate problems with teaching and advising in SME majorsexplaining gender differences in attrition rates. Journal of College Science Teaching, 21, 284-292.

Silver, W. S., Mitchell, T. R., \& Gist, M. E. (1995). Responses to successful and unsuccessful performance: The moderating effect of self-efficacy on the relationship between performance and attributions. Organizational Behavior and Human Decision Processes, 62(3), 286-299. https://doi.org/10.1006/obhd.1995.1051

Skaalvik, E. M., Federici, R. A., \& Klassen, R. M. (2015). Mathematics achievement and self-efficacy: Relations with motivation for mathematics. International Journal of Educational Research, 72, 129-136. https://doi.org/10.1016/j.ijer.2015.06.008

Stanton, J. D., Neider, X. N., Gallegos, I. J., \& Clark, N. C. (2015). Differences in metacognitive regulation in introductory biology students: when prompts are not enough. CBE-Life Sciences Education, 14(2), ar15. https://doi.org/10.1187/cbe.14-08-0135 
Stout, J. G., Dasgupta, N., Hunsinger, M., \& McManus, M. A. (2011). STEMing the tide: using ingroup experts to inoculate women's self-concept in science, technology, engineering, and mathematics (STEM). Journal of personality and social psychology, 100(2), 255. https://doi.org/10.1037/a0021385

Sullivan, J. R., \& Guerra, N. S. (2007). A closer look at college students: Self-efficacy and goal orientation. Journal of Advanced Academics, 18(3), 454-476. https://doi.org/10.4219/jaa-2007-500

Van Der Meer, J., Jansen, E., \& Torenbeek, M. (2010). 'It's almost a mindset that teachers need to change': first-year students' need to be inducted into time management. Studies in Higher Education, 35(7), 777-791. https://doi.org/10.1080/03075070903383211

Vitali, J., Blackmore, C., Mortazavi, S., \& Anderton, R. (2020). Tertiary Anatomy and Physiology, a Barrier for Student Success. International Journal of Higher Education, 9(2), 289-296. https://doi.org/10.5430/ijhe.v9n2p289

Vosniadou, S. (2020). Bridging Secondary and Higher Education. The Importance of Self-regulated Learning. European Review, 28(S1), S94-S103. https://doi.org/10.1017/S1062798720000939

Winne, P. H. (2018). Cognition and metacognition within self-regulated learning. Educational psychology handbook series. Handbook of self-regulation of learning and performance (pp. 36-48). Routledge/Taylor \& Francis Group. https://doi.org/10.4324/9781315697048-3

Winne, P. H., \& Hadwin, A. F. (2013). nStudy: Tracing and supporting self-regulated learning in the Internet. In International handbook of metacognition and learning technologies (pp. 293-308). Springer, New York, NY. https://doi.org/10.1007/978-1-4419-5546-3_20

Wright, S. L., Jenkins-Guarnieri, M. A., \& Murdock, J. L. (2013). Career development among first-year college students: College self-efficacy, student persistence, and academic success. Journal of Career Development, 40(4), 292-310. https://doi.org/10.1177/0894845312455509

Zell, E., \& Krizan, Z. (2014). Do People Have Insight Into Their Abilities? A Metasynthesis. Perspect Psychol Sci, 9(2), 111-25. https://doi.org/10.1177/1745691613518075

Zimmerman, B. J. (1990). Self-regulated learning and academic achievement: An overview. Educational psychologist, 25(1), 3-17. https://doi.org/10.1207/s15326985ep2501_2

Zimmerman, B. J. (2000). Self-efficacy: An essential motive to learn. Contemporary educational psychology, 25(1), 82-91. https://doi.org/10.1006/ceps.1999.1016

Zimmerman, B. J. (2002). Becoming a self-regulated learner: An overview. Theory into practice, 41(2), 64-70. https://doi.org/10.1207/s15430421tip4102_2

Zimmerman, B. J., \& Bandura, A. (1994). Impact of self-regulatory influences on writing course attainment. American Educational Research Journal, 31(4), 845-862. https://doi.org/10.3102/00028312031004845

Zimmerman, B. J., Bonner, S., Evans, D., \& Mellins, R. B. (1999). Self-regulating childhood asthma: a developmental model of family change. Health Education \& Behavior, 26(1), 55-71. https://doi.org/10.1177/109019819902600106

Zimmerman, B. J., \& Martinez-Pons, M. (1992). Perceptions of efficacy and strategy use in the self-regulation of learning. In Student perceptions in the classroom, 185-207. Routledge.

Zimmerman, B. J., \& Moylan, A. R. (2009). Self-regulation: Where metacognition and motivation intersect. In Handbook of metacognition in education (pp. 311-328). Routledge.

Zimmerman, B. J., Moylan, A., Hudesman, J., White, N. \& Flugman, B. (2011). Enhancing self-reflection and mathematics achievement of at-risk urban technical college students. Psychological Test and Assessment Modelling, 53(1), 141-160.

Zimmerman, B. J., \& Schunk, D. H. (2011). Motivational sources and outcomes of self-regulated learning and performance. Handbook of self-regulation of learning and performance, 5(3), 49-64.

\section{Copyright}

Copyright for this article is retained by the author(s), with first publication rights granted to the journal.

This is an open-access article distributed under the terms and conditions of the Creative Commons Attribution license (http://creativecommons.org/licenses/by/4.0/). 